\title{
In-situ synchrotron characterisation of fracture initiation and propagation in shales during indentation
}

\author{
Lin $\mathrm{Ma}^{1 *}$, Anne-Laure Fauchille ${ }^{2}$, Michael R. Chandler ${ }^{1}$, Patrick Dowey ${ }^{1}$, Kevin G.Taylor ${ }^{1}$, \\ Julian Mecklenburgh ${ }^{1}$, Peter D. Lee ${ }^{3,4}$,
}

${ }^{1}$ Department of Earth and Environmental Sciences, The University of Manchester, Oxford Road, Manchester, M13 9PL, UK.

${ }^{2}$ Centrale Nantes, Institut de recherche en Génie civil et Mécanique (GeM) - UMR CNRS 6183, 1 rue de la Noe, 44321 Nantes cedex 3, France

${ }^{3}$ UCL Mechanical Engineering, Torrington Place, London, WC1E 7JE, UK.

${ }^{4}$ Research Complex at Harwell, Rutherford Appleton Laboratory, Didcot Oxon OX11 0FA, UK.

* Corresponding author: Lin Ma (lin.ma@,manchester.ac.uk)

\section{Highlights:}

- In-situ synchrotron imaging is demonstrated to investigate fracturing in shales

- 3D images were recorded during stepped loading and used to perform digital volume correlation

- The deformation zones were quantitatively resolved

- Composition, texture and orientation influence fracture initiation and propagation

\begin{abstract}
The feasibility and advantages of synchrotron imaging have been demonstrated to effectively characterise fracture initiation and propagation in shales during indentation tests. These include 1) fast (minute-scale) and high-resolution ( $\mu \mathrm{m}$-scale) imaging of fracture initiation, 2 ) concurrent spatial and temporal information (4D) about fracture development, 3) quantification and modelling of shale deformation prior to fracture. Imaging experiments were performed on four shale samples with different laminations and compositions in different orientations, representative of three key variables in shale microstructure. Fracture initiation and propagation were successfully captured in 3D over time, and strain maps were generated using digital volume correlation (DVC). Subsequently, post-experimental fracture geometries were characterized at nano-scale using complementary SEM imaging. Characterisation results highlight the influence of microstructural and anisotropy variations on the mechanical properties of shales. The fractures tend to kink at the interface of two different textures at both macroscale and microscale due to deformation incompatibility. The average composition appears to provide the major control on hardness and fracture initiation load; while the material texture and the orientation of the indentation to bedding combine to control the fracture propagation direction and geometry. This improved understanding of fracture development in shales is potentially significant in the clean energy applications.
\end{abstract}




\section{Introduction}

Shales play a significant role in the energy transition from conventional resources (e.g. coal and oil) towards less carbon intensive sources of energy such as natural gas (e.g. Aalto et al., 2017; Arif et al., 2017; Ren et al., 2015), long-term geological storage of $\mathrm{CO}_{2}$ and radioactive waste (Fauchille et al., 2016; Hedan et al., 2018) and short-term subsurface energy storage of hydrogen and heat (Charlet et al., 2017). Shale formations are naturally tight, but effective permeability can be increased through stimulated fractures (Rutter and Mecklenburgh, 2017). Therefore, the initiation and propagation of fractures in shales is of wide interest, especially in environmental applications.

Previous studies have undertaken mechanical tests to investigate fracture mechanics properties on shale samples. This has included fracture initiation and propagation pressure measurements during hydraulic fracturing (Feng et al., 2016), Brazilian disk (Nezhad et al., 2018), Semicircular bend (Forbes-Inskip et al., 2018) or indentation (Fan et al., 2019) experiments. However, shales are highly heterogeneous materials in which macroscopic deformation is controlled by microscale features. Microstructural anisotropy is a particularly important control on the initiation and propagation of artificial fractures (Chandler et al., 2016; Guo et al., 2012; Lee et al., 2015). The initiation location and development of fractures are correlated to microstructural heterogeneities related to the orientation and concentration of rigid grains and soft organic matter (Fauchille et al., 2014; Figueroa Pilz et al., 2017). These relationships between microstructure and strains are difficult to quantify in the laboratory (Fauchille et al., 2019). Advanced mechanical tests can characterise fracture propagation measured by pressure curves, through optical and electron microscopy ( $\mathrm{nm}$ to $\mathrm{mm}$ ) techniques on the $2 \mathrm{D}$ surface of the material (Chandler et al., 2018), or post-experimentally in 3D by X-ray Computed Tomography (XCT) (Lovell et al., 2018). Despite great progress, the spatial and temporal development of the fracture still cannot be determined in 3D using these techniques, and this information is critical to understand the natural and anthropogenic fracture propagation. Timelapse XCT (4D; 3D plus time) imaging is a powerful tool to investigate shale microstructure and fracture development (Chandler et al., 2018; Figueroa Pilz et al., 2017; Ma et al., 2017), as well as other materials (e.g. Cai et al., 2016; Karagadde et al., 2015; Kareh et al., 2014; Mo et al., 2018). This imaging provides a unique opportunity to understand the mechanisms of fracture initiation and propagation, providing guidance for industrial operations and environmental impact controls.

Presently, little is known about the spatial characteristics of propagating fractures in heterogeneous shales, especially at the microstructural scale, and how variations in local microstructural heterogeneities can affect fracture geometries. This paper aims to spatially and temporally track the propagation of fractures during indentation tests using a novel experimental methodology, in-situ synchrotron X-ray tomography. From data collected on samples of varying composition and microstructure at varying orientations, microstructural controls on fractures can be elucidated. This work leads to an improved understanding on the relationship between shale microstructure and mechanical properties and the method demonstrably has broad potential applications in applied subsurface energy extraction, seasonal storage of hydrogen and heat, permanent waste disposal and relative environmental assessment. 


\section{Materials and methods}

\subsection{Experimental materials}

Samples of four reference shale formations from the UK and USA (Table 1) were selected to assess the influence of varying microstructure and composition on fracture development. Between these, the primary sample selection criteria is microstructural variation. Four degrees of laminations, unlaminated (the Bowland shale formation; BSF; Fauchille et al., 2017), poorly-laminated (the Whitby Mudstone Formation; WMF; McKernan et al., 2017), thicklylaminated (the Kimmeridge Clay Formation; KCF; Hawthorn et al., 2004; lamina thickness 1.5 $\mathrm{mm}$ ), and finely-laminated (the Haynesville-Bossier Shale; HBS; Ma et al., 2019; Ma et al., 2018), were selected. The average laminae number (LN) per $\mathrm{cm}$ in these samples are $0,6,8$, 13 respectively.

The secondary criteria is the mineral composition. The samples are all natural rocks and matching the exact same compositions with different textures is impossible. The selected four samples have relatively similar compositions without dramatic variations to ensure that microstructure variation is still the primary variable while also allowing comparison between compositions. Among them, BSF has highest carbonate content while the WMF has highest clay minerals and KCF is highest in silicate. HBS has moderate values in these compositions. The orientations are then the third parameter. All selected samples were prepared at three orientations with respect to the bedding planes: bedding perpendicular $\left(0^{\circ}\right)$, bedding inclined $\left(45^{\circ}\right)$ and bedding parallel $\left(90^{\circ}\right)$.

\subsection{Sample preparation}

To assess how orientation to bedding influences fracture development, shale cylinders $(3 \mathrm{~mm}$ diameter and approximately $5 \mathrm{~mm}$ length) were prepared by a microdrill with the cylinder long axes in three different orientations: $0^{\circ}, 45^{\circ}$ and $90^{\circ}$ (Figure 1a). Each cylinder was then mounted within a Kapton Tube (Figure $1 \mathrm{~b}$ ). Each tube was then filled by epoxy resin to surround the shale samples. Shales are very low permeability materials so the resin is unlikely to penetrate the samples.

The top surface of each sample was finely polished by dry carbide and diamond polishing agent to ensure a flat surface below the indenter (Figure $1 \mathrm{~b}$ and c). Each shale cylinder was scanned prior to the experiments, to verify that the microstructure of the sample was representative of the bulk material, and that anomalous macroscopic features (e.g. fractures or mineral veins) were not present. The samples with significant pre-existing fractures (as a consequence, with possible resin inside) were therefore not taken into account in this research. This sampling bias is commonplace but difficult to avoid when working with shale samples, as samples containing large fracture populations are inherently more difficult to prepare (Chandler et al., 2016). After polishing, each sample was mounted in the rig and aligned to the indenter using a laser (Figure 1e). More details can be found in Figure S1 of the supporting materials.

\subsection{Experimental method}

The indenter and shale cylinder were mounted in the bespoke P2R nano-precision mechanical test rig (Karagadde et al., 2015; Kareh et al., 2014), (Figure $1 \mathrm{~d}$ and e). A vertical load ( \pm $0.1 \mathrm{~N}$ ) was applied using a square-based diamond pyramid Vickers indenter. An internal displacement sensor (LVDT) was used to control the vertical displacement of the indenter ( \pm $1 \mu \mathrm{m})$. 
Table 1. Characterization and mechanical measurements of the studied shale samples (scale bar $=\mathbf{2} \mathbf{m m}$; for uncertainties, see Table 2).

\begin{tabular}{|c|c|c|c|c|c|c|c|c|c|c|c|}
\hline \multirow{2}{*}{ Samples } & \multirow{2}{*}{ Texture } & \multirow{2}{*}{$\begin{array}{c}\text { TOC } \\
(\text { wt. \%) }\end{array}$} & \multicolumn{3}{|c|}{ TOC corrected XRD (wt. \%) } & \multirow{2}{*}{$\mid \begin{array}{l}\text { Porosit } \\
\mathbf{y}(\%)\end{array}$} & \multirow{2}{*}{$\begin{array}{l}\text { Lamina number } \\
\operatorname{per} \mathrm{cm}(\mathrm{LN})\end{array}$} & \multirow{2}{*}{$\begin{array}{c}\text { Bedding } \\
\text { orientation relative } \\
\text { to horizontal }\left({ }^{\circ}\right)\end{array}$} & \multirow{2}{*}{ Peak load (N) } & \multirow{2}{*}{$\begin{array}{c}\text { Contact } \\
\text { area }\left(\mathrm{mm}^{2}\right)\end{array}$} & \multirow{2}{*}{$\begin{array}{c}\text { Vickers } \\
\text { hardness } \\
\text { (GPa) }\end{array}$} \\
\hline & & & Silicate & Carbonate & Clay & & & & & & \\
\hline \multirow{3}{*}{$\begin{array}{c}\text { Bowland Shale } \\
\text { Formation } \\
\text { (BSF; UK) }\end{array}$} & unlaminated & \multirow{3}{*}{3.2} & \multirow{3}{*}{40.9} & \multirow{3}{*}{52.4} & \multirow{3}{*}{3.5} & \multirow{3}{*}{4} & \multirow[t]{3}{*}{$\mathbf{0}$} & $\mathbf{0}$ & 198.1 & $0.348 \times 0.336$ & 3.08 \\
\hline & & & & & & & & 45 & 218.8 & $0.360 \times 0.360$ & 3.07 \\
\hline & & & & & & & & 90 & 206.9 & $0.295 \times 0.286$ & 4.46 \\
\hline \multirow{3}{*}{$\begin{array}{c}\text { Whitby } \\
\text { Mudstone } \\
\text { Formation } \\
\text { (WMF; UK) }\end{array}$} & Poorly-laminated & \multirow[b]{3}{*}{2.3} & \multirow[b]{3}{*}{53.5} & \multirow[b]{3}{*}{2.6} & \multirow[b]{3}{*}{41.5} & \multirow[b]{3}{*}{7} & \multirow[t]{3}{*}{6} & 0 & 62.6 & $0.434 \times 0.428$ & 0.61 \\
\hline & & & & & & & & 45 & 90.1 & $0.375 \times 0.383$ & 1.14 \\
\hline & & & & & & & & 90 & 78.4 & $0.322 \times 0.316$ & 1.40 \\
\hline \multirow{3}{*}{$\begin{array}{l}\text { Kimmeridge } \\
\text { Clay Formation } \\
\text { (KCF; UK) }\end{array}$} & thickly-laminated & \multirow{3}{*}{7.8} & \multirow{3}{*}{55.0} & \multirow{3}{*}{9.2} & \multirow{3}{*}{27.9} & \multirow{3}{*}{7} & \multirow[t]{3}{*}{8} & $\mathbf{0}$ & 81.6 & $0.420 \times 0.412$ & 0.86 \\
\hline & ( & & & & & & & 45 & 34.0 & $0.520 \times 0.520$ & 0.23 \\
\hline & 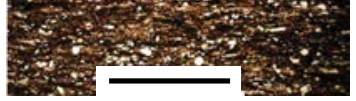 & & & & & & & 90 & 35.9 & $0.410 \times 0.430$ & 0.37 \\
\hline \multirow[b]{3}{*}{$\begin{array}{c}\text { Haynesville- } \\
\text { Bossier Shale } \\
\text { (HBS; US) }\end{array}$} & Finely-laminated with & \multirow[b]{3}{*}{4.5} & \multirow[b]{3}{*}{41.6} & \multirow[b]{3}{*}{17.3} & \multirow[b]{3}{*}{36.6} & & 13 & $\mathbf{0}$ & 32.8 & $0.410 \times 0.410$ & 0.35 \\
\hline & & & & & & & & 45 & 23.0 & $0.366 \times 0.382$ & 0.30 \\
\hline & $\frac{-7}{+\frac{1}{2}}$ & & & & & 7 & & 90 & 26.0 & $0.320 \times 0.324$ & 0.46 \\
\hline
\end{tabular}


The experiments were performed with the deformation rig mounted on beamline I13-2 at Diamond Light Source using a pink X-ray beam coupled with a PCO Edge camera (Beamtime MT 15506). The experiments started from $0 \mathrm{~N}$ with the indentor touching the sample top surface without any force $(0 \mathrm{~N})$. A 3D X-ray tomography was acquired (voxel size: $1.6 \mu \mathrm{m}$ ) in 90 seconds as the reference image. In order to detect and capture fracture initiation, the indenter displacement was applied in discrete steps of 15 to $30 \mu \mathrm{m}$. After each displacement step, a 3D Xray tomography was acquired (voxel size: $1.6 \mu \mathrm{m}$ ) and the force was recorded all through the experiments. Each scan was composed of 1800 projections. Multiple 3D images over time (4D) provide temporal information on the ongoing deformation and fracture progression during loading. Indentation tests were performed on 12 samples (4 different rocks, with 3 orientations each) in total (Table 1). Repeated experiments were conducted for a few selected samples (e.g. BSF $0^{\circ}$ and $\mathrm{HBS} 180^{\circ}$ ) for uncertainty control, but were not possible for all materials and orientations within the time period of synchrotron beamtime access. Following the experiments, all samples were impregnated with resin, cut and polished for high-resolution vertical cross section maps $(3 \mathrm{~mm} \times 3 \mathrm{~mm})$ under SEM $(37 \mathrm{~nm}$ pixel size $)$.

(a)

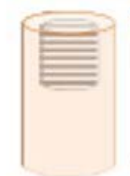

$0^{\circ}$

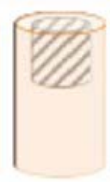

$45^{\circ}$

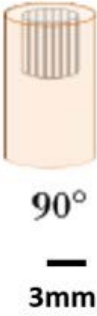

(b)

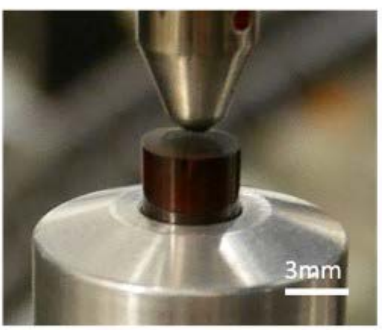

(c)

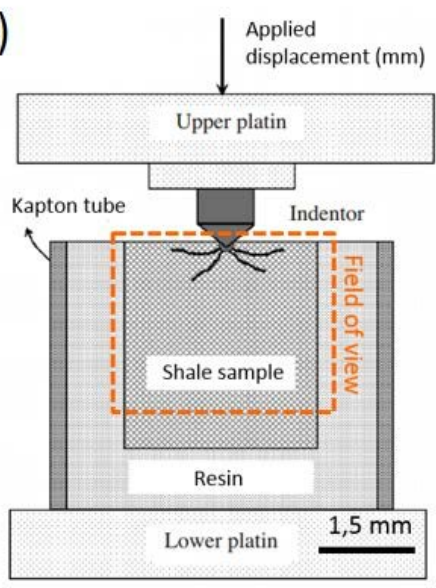

(d)
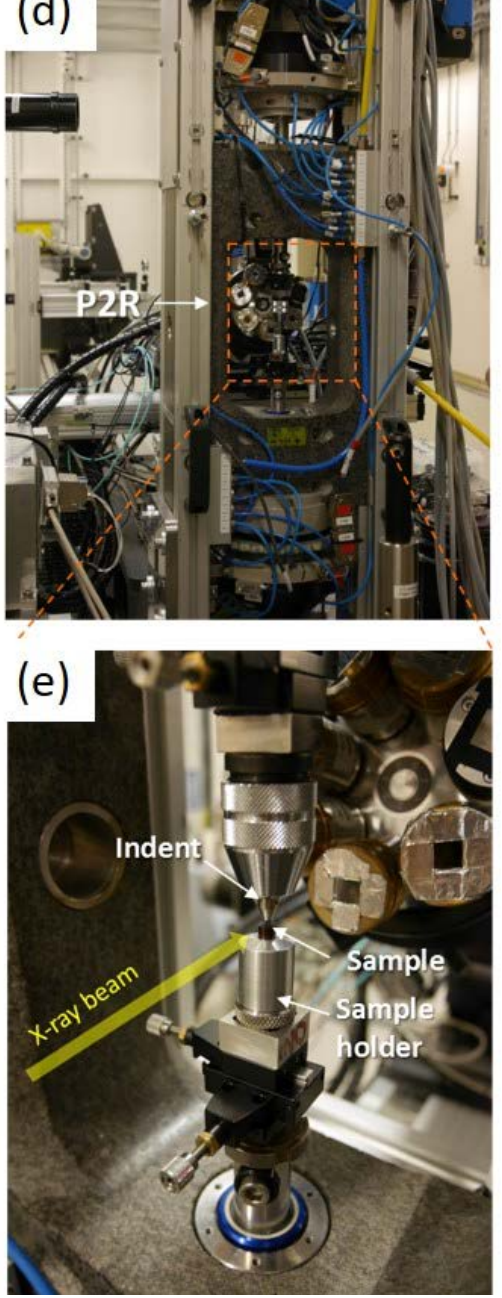
Figure 1. In-situ synchrotron indentation experiment. a. sample orientations; b. sample and sample holder; c. schematic of the indentation process; d. P2R compression rig on the I13 beam line, Diamond Light Source; e. close-up of d.

\subsection{Image processing and quantification}

A filtered back-projection algorithm was used to reconstruct the 3-D tomographic datasets and remove ring artifacts (Titarenko et al., 2010). Each reconstructed 3-D dataset had dimensions of $800 \times 600 \times 600$ voxels.

Image processing and analysis was performed using Avizo 9.5 (FEI, France) and ImageJ (US NIH, USA). Time-lapse images were registered, and filtered by a 3D non-local means filter algorithm (search window 21, local neighborhood 5, similarity 0.6) to reduce noise (Buades et al., 2005). The fractures were then segmented on the basis of grey levels on the 3D images.

3D digital volume correlation (DVC) was applied to measure the displacement fields and calculate strain fields during the indentation using Davis 8.3 software. Three-step window sizes were used (128 voxels; 64 voxels; 48 voxels; 2 passes and 50\% overlap). The final spatial resolution of the displacement and strain field corresponds to $76.8 \mu \mathrm{m}$.

\subsection{Vickers hardness calculation}

Hardness measures the resistance to localized deformation which was induced by indentation. Vickers hardness $\left(H_{\mathrm{V}}\right)$ was calculated from the contact area of the impression produced under load (Broitman, 2017):

$H_{\mathrm{V}}(G P a)=0.0018544 \frac{L}{d^{2}}$

Where $L$ is indentation load $(\mathrm{N})$ and $d(\mathrm{~mm})$ is equal to the length of the diagonal measured from corner to corner on the residual impression in the specimen surface.

Fracture toughness $\left(K_{\text {Ic }}\right)$ was measured using the method described by Anstis et al. (1981) (see supporting information), but the assumption of penny-shaped fractures is not found to be valid in these materials, and leads to underestimates of $K_{\text {Ic. }}$.

\subsection{Uncertainty analysis}

The uncertainties of TOC, XRD, porosity, indentation load, displacement measurements are determined by mechanical errors (Table 2).

Uncertainty analyses of derived measurements were conducted using Kline-Mcclintock method (Kline and McClintock, 1953) following the quantification (1) to determine the uncertainty associated with the hardness calculation (Table2).

$$
\begin{gathered}
\xi=\mathrm{f}(\beta 1, \beta 2, \ldots, \beta \mathrm{n}) \\
\Delta \xi=\sqrt{\sum_{i=1}^{n}\left(\frac{\partial \Sigma}{\partial \beta_{i}} \Delta \beta_{i}\right)^{2}}
\end{gathered}
$$

where a value $\xi$ has the uncertainty of $\Delta \xi$ calculated from the independent variables $\beta \mathrm{i}$ and their uncertainties $\Delta \beta \mathrm{i}$.

Hardness is calculated using equation (1) and depends on the measurement of $L$ and $d$. The indentation load $\mathrm{L}(\mathrm{N})$ is equipment uncertainty which was determined to be $0.1 \mathrm{~N}$ while the contact area $d$ was measured in the images and the uncertainty was estimated as $4.8 \times 4.8 \mu \mathrm{m}^{2}(3$ 
$\times 3$ pixels). Therefore, the uncertainty calculated using equations (2) and (3) is $0.2 \mathrm{~N} / \mathrm{mm}^{2}$ or $0.0002 \mathrm{GPa}$.

The uncertainty of fracture propagation or geometry is determined by fracture segmentation, when segmentation error is considered to be $3 \times 3 \times 3$ pixels, as $110.6 \mu \mathrm{m}^{3}$.

Table 2 Parameters and results of the uncertainty analysis

\begin{tabular}{|l|l|l|l|}
\hline & Variable & Uncertainty & Units \\
\hline \multirow{4}{*}{ Measurements } & TOC & 0.1 & $\%$ \\
\cline { 2 - 4 } & XRD & 0.1 & $\%$ \\
\cline { 2 - 4 } & Porosity & 0.1 & $\%$ \\
\cline { 2 - 4 } & Indentation load L & 0.1 & $\mathrm{~N}$ \\
\cline { 2 - 4 } & Contact area d & 0.05 & $\mathrm{~mm}^{2}$ \\
\cline { 2 - 4 } & displacement & 30 & $\mu \mathrm{m}$ \\
\hline Hardness & Hardness Hv & 0.02 & $\mathrm{GPa}$ \\
\hline Fracture volume & image segmentation & 110.6 & $\mu \mathrm{m}^{3}$ \\
\hline
\end{tabular}

\section{Results}

The real-time tomographic imaging of indentation in shales provides qualitative and quantitative analysis of deformation, fracture initiation and propagation in shales. The influence of composition, microstructure and sample orientation on shale mechanical properties are then analyzed based on the synchrotron images.

\subsection{Vickers hardness of the samples}

The Vickers Hardness $\left(H_{\mathrm{V}}\right)$ of each studied sample was calculated using Equation 1 (Table 1). BSF samples have the greatest $H_{\mathrm{V}}(3.07-4.46 \mathrm{GPa})$ overall, followed by the WMF $(0.61-1.40$ $\mathrm{GPa})$ and $\mathrm{KCF}(0.23-0.87 \mathrm{GPa})$. The HBS samples have the lowest $H_{\mathrm{V}}(0.30-0.46 \mathrm{GPa}$. When compared with compositions, BSF has significantly higher carbonate content than the other three samples, corresponding to the highest Hv values for all three orientations (Figure 2a). The other three samples have relatively similar compositions in carbonate, silicate and ductile materials including organic matter and clay minerals.

The peak loads (Figure 2b) and Hv (Figure 2c) do not vary systematically with orientation within each sample set. Both the BSF and WMF have the greatest peak load at $45^{\circ}$ and greatest $H_{\mathrm{V}}$ at $90^{\circ}$, while the $\mathrm{KCF}$ and the $\mathrm{HBS}$ have greatest peak load and $\mathrm{Hv}$ at $0^{\circ}$. The laminations of the former two samples are not obvious (unlaminated BSF- LN0, and poorly laminated KCF - LN6), therefore the orientations of these two samples are not representative entirely. For laminated samples, the results were interpreted by an easier access to interfaces and pre-existing defaults (some of them are in the same direction than the displacement of the indent), which facilitate a vertical crack opening and reduce the contact surface below the indent. The difference between peak load and peak Hv measurement is caused by the differing contact area measured in the images (Table 1). The uncertainly of contact area measures $\left(23 \mu \mathrm{m}^{2}\right)$ and the slight difference in lag time between the load measurement and tomograph recording taken after the initial fracture appearance $(<2$ seconds) may also affect this variation. 

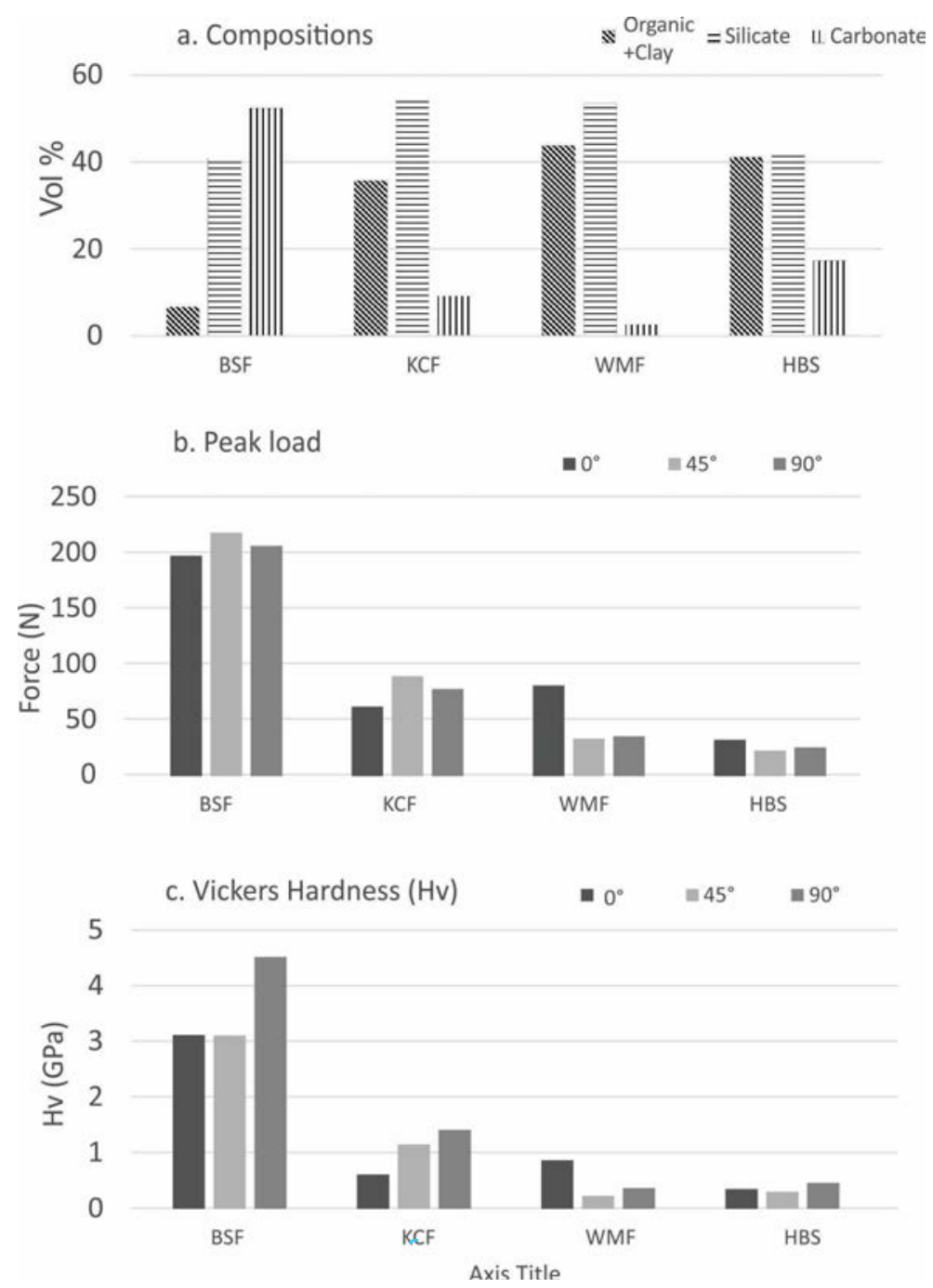

Figure 2 Compositions (a), peak load (b) and Vickers Hardness (c) of the four selected samples at three orientations

\subsection{Fracture initiation and propagation}

With increasing load, brittle deformation of samples produced fractures which initiated beneath the indenter and propagated to the sample edges (e.g. Figure 3). The peak-applied load (Table 1) varied between materials and sample orientations as described in Section 3.1. BSF and KCF samples are selected in this section for comparison between the form of fractures propagating within different shale textures (LN 0, 6, 8 13).

In the BSF (unlaminated, LN0), fractures in all three orientations initiated directly beneath the indenter and propagated vertically down into the sample (Figure $3 \mathrm{~A}$ ). In each case, after fracture initiation the load relaxed. As the load was subsequently increased, the original crack widened, continued to propagate vertically, and in some cases bifurcated. In the $0^{\circ}$ (bedding perpendicular) sample, a single planar fracture initiated and propagated to the base of the sample. In the $90^{\circ}$ (bedding parallel) sample, three branching fractures were observed at peak load. In the $45^{\circ}$ (bedding inclined) sample, one initial fracture developed at peak load, and additional 
branches formed as the load subsequently increased. Propagation directions were insensitive to bedding orientation in this unlaminated material.

In KCF (thickly laminated, LN8) samples, fractures initiated directly beneath the indenter, and were similar to the initial BSF fractures. However, these fractures propagated through the KCF samples differently (Figure 3B). In the $0^{\circ}$ sample, the initiation fracture deflected to lie parallel to the bedding plane upon reaching the interface of two laminations. Subsequent fractures initiated at the deflection point of the original fracture and propagated along the bedding interface. In the $45^{\circ}$ and $90^{\circ}$ samples, the original fractures propagated parallel to the bedding planes. During postinitiation reloading, the initial fractures widened, but no further fractures were generated. 


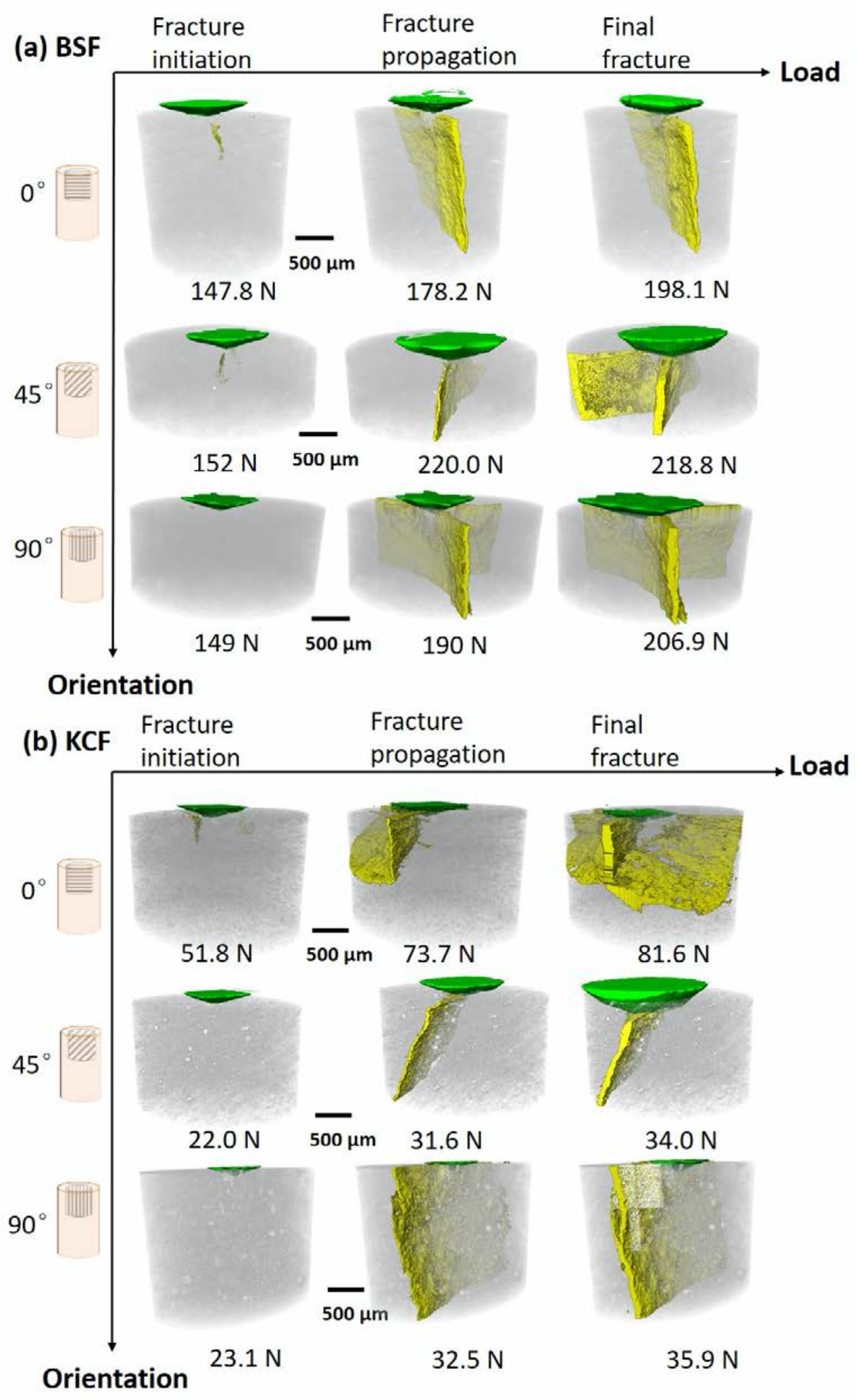

Figure 3 3D images of fracture initiation and progressive propagation in samples from the BSF (a) and KCF (b) at different orientations 


\subsection{Strains during indentation}

Figure 4 shows the strain localization, quantified by DVC, with corresponding XCT slices for two samples oriented at $0^{\circ}$, an unlaminated sample (BSF, LN0) and a laminated sample (KCF, LN8) for comparison.

Some initial deformation was observed beneath the indenter under low loading in both samples (Figure $4 \mathrm{a} 2-\mathrm{a} 3$ and $\mathrm{c} 2-\mathrm{c} 3$ ) compared with the original image (Figure $4 \mathrm{a} 1$ and $\mathrm{c} 1$ ). The strain prior to fracture generation calculated on the basis of displacement derivative is relatively evenly distributed in the BSF sample (LN0, Figure 4 b1-b2 and d1-d2) but in the laminated KCF sample (LN8), the strain distribution is heterogeneous, with strains directly beneath the indenter. When the load increased further, fractures began to nucleate. The strains in the BSF sample became localized around the fractures (Figure $4 \mathrm{~b} 3$ ), while those in KCF sample are still heterogeneous, (Figure $4 \mathrm{~d} 3$ ). In the post-fracturing stage, the strains mainly increased in one side of the main fractures in both samples (Figure 4 b4 and d4), suggesting sliding on the newly developed fracture.
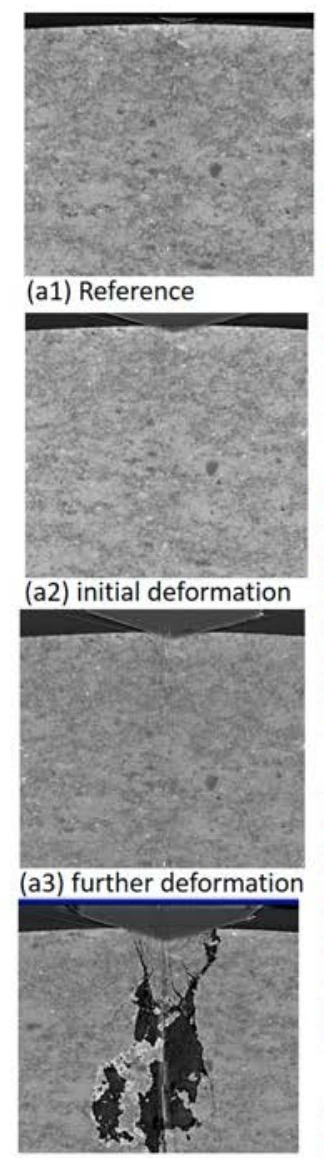

(a4) cracks

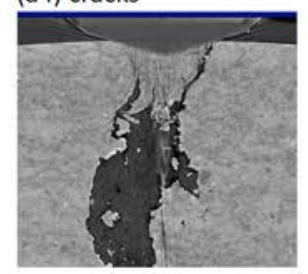

(a5) post cracks
BSF $0^{\circ}$ sample

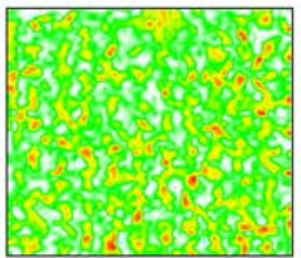

$$
\text { (b1) }
$$

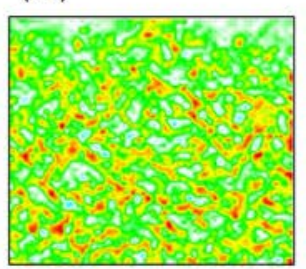

(b2)

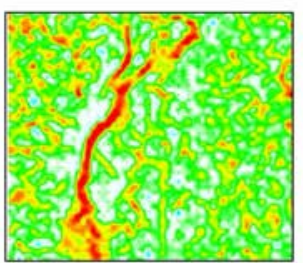

(b3)

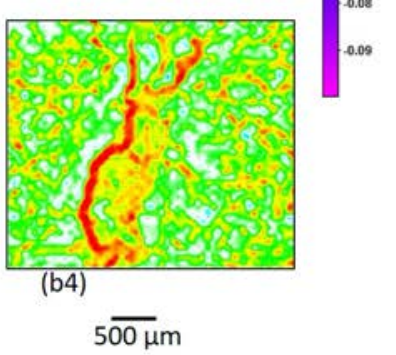

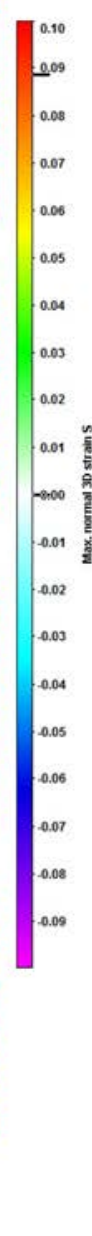

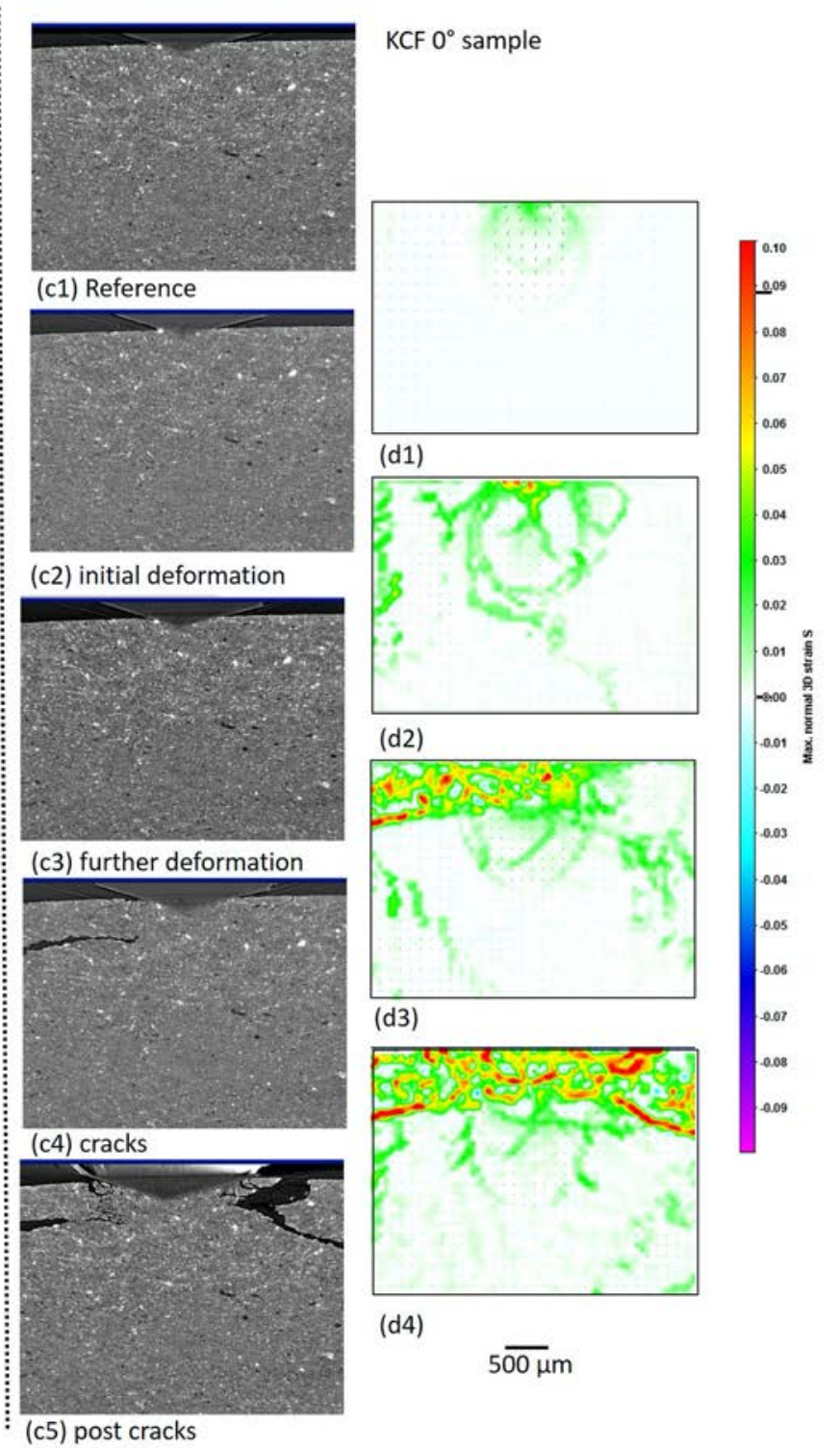


Figure 4 Deformation and fracture propagation in an unlaminated sample (BSF, LN0, $\left.0^{\circ}\right)$ and a laminated sample (KCF, LN8, $0^{\circ}$ ); a and c by XCT slices, b and d by DVC strain maps.

\subsection{Fracture propagation and branching}

The geometries of the 3D fractures in different samples are presented and summarized in Figure 5. In all orientations, fractures in unlaminated samples (e.g. BSF, LN0) propagated vertically without any deflection, while in the laminated samples, propagation directions varied with orientation. For bedding-perpendicular loading, fractures deflected toward the bedding planes at the interface of two laminations. The fracture geometries become relatively complex when the lamination patterns are complex (e.g. WMF, LN6). The fractures at the interface followed preexisting cracks in the HBS samples (LN13). At $45^{\circ}$ (bedding inclined) and $90^{\circ}$ (bedding parallel), fractures in all laminated samples initiated directly beneath the indenter and propagated parallel to the bedding interfaces.

\begin{tabular}{|c|c|c|c|c|c|c|}
\hline \multirow[t]{2}{*}{ Samples } & \multicolumn{3}{|c|}{ Experimental fractures } & \multicolumn{3}{|c|}{ Fracture models } \\
\hline & $0^{\circ}$ & $45^{\circ}$ & $90^{\circ}$ & $0^{\circ}$ & $45^{\circ}$ & $90^{\circ}$ \\
\hline BSF & & & & & & \\
\hline KCF & & & & & & \\
\hline WMF & & & & & & \\
\hline HBS & & & & & & \\
\hline
\end{tabular}

Figure 5 3D experimental fracture geometries and fracture models of 4 materials in 3 orientations. Green- indenter, yellow- experimental fractures, red- fracture models, bluepre-existing cracks.

\subsection{Nanoscale fracture imaging in bedding-perpendicular samples}

Due to resolution limitations on the tomography images $(\sim 3 \mu \mathrm{m})$, post-failure fractures with aperture $<3 \mu \mathrm{m}$ are imaged using high-resolution SEM mapping of 2D sections through the sample. Samples at $0^{\circ}$ were selected (Figure 6) for comparison owing to the greater differences in 
fracture geometry between materials. The interaction of fractures and microstructures can be further analyzed at nanoscale.

In the highly cemented and non-laminated sample (e.g. BSF, LN0), no obvious nanoscale fractures were observed, while the major fracture penetrates through the entire sample perpendicular to the bedding (Figure 6 a-c). In the clay-rich and laminated sample (e.g. KCF, LN8), the major fractures run through the sample with a $45^{\circ}$ angle to the bedding direction. These fractures consist of continuous ' $Z$ ' shape segments (Figure $6 \mathrm{~d}$-f). Secondary branches of these fractures developed at a similar angle and propagated parallel to the elongate clay mineral grain orientations (Figure $6 \mathrm{~d}$ ). These fractures bypass the 'hard' carbonate grains and pyrite framboids via rounded corners (Figure $6 \mathrm{~d}-\mathrm{f}$ ). New sub-branches initiated at the sharp corners of the carbonate grains and developed along the surrounding clay minerals. These sub-branches continue to propagate following clay mineral orientations. In the poorly laminated sample (e.g. WMF, LN6), the major fractures penetrated through the sample while the secondary branches lay along similar orientations to the bedding planes at the microscale. Nanoscale fractures also followed the local clay mineral orientations which sometimes differ from the overall bedding planes (Figure $6 \mathrm{~g}$-i). The relatively intricate matrix leaded to the complex fracture pattern. In the samples with preexiting fractures (e.g. HBS, LN13), most nanoscale fractures were in alignment with the major fractures at the microscale (Figure $6 \mathrm{j}-1)$, and this alignment is particularly prominent when in the same orientation with bedding planes.

In summary, the nano-fracture networks depend on the degree of the cementation and the arrangement of mineral grains in the matrix. The geometry and distribution of 'hard' minerals (i.e. carbonate minerals, pyrite grains, and cemented silica gains) and the local orientations of 'soft and sheet' clay minerals are major controls on the major fracture propagation direction. 

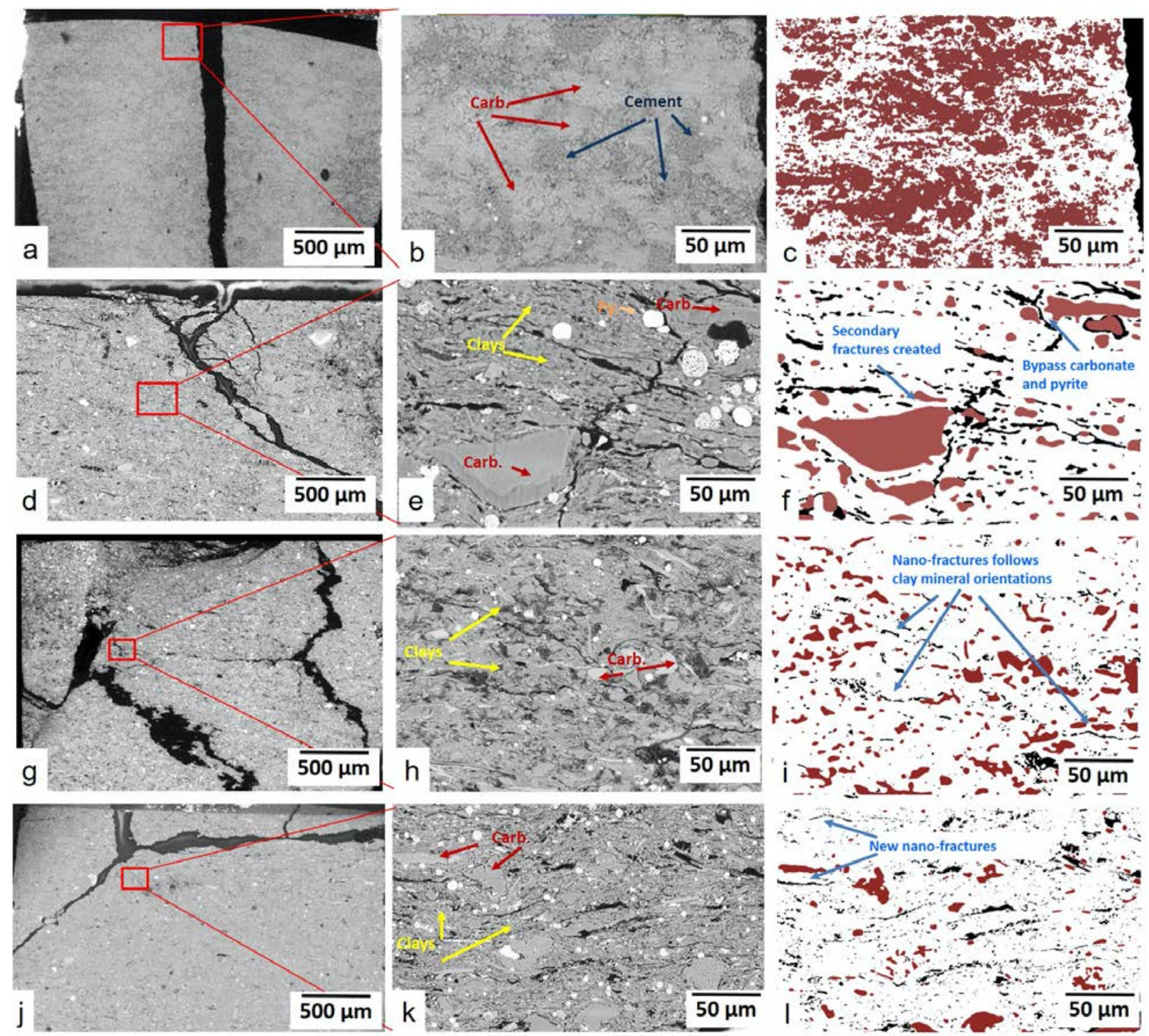

Figure $6 \mathrm{SEM}$ image (Backscatter) of nanoscale fractures in samples at $0^{\circ}$ (bedding perpendicular). a-b: BSF; d-e: KCF; g-h: WMF; j-k: HBS. Clays-clay minerals, carb.carbonate grains, py.- pyrite framboids. In $\mathrm{c}, \mathrm{f}, \mathrm{i}$ and $\mathrm{l}$, red refers to the granular mineral grains and the black refers to the fractures segmented in the SEM images.

\section{Discussion}

\subsection{Advantages and disadvantages of synchrotron imaging for fracture propagation quantification in shales}

Many mechanical properties, for example, indentation hardness, can be extracted from standard indentation tests. Synchrotron images provide four dimensional information, spatial and temporal, to characterize and quantify the fractures initiation and growth. The spatial and temporal information is crucial for fracture propagation prediction when affected by microstructure, especially in highly heterogeneous samples like shales. 
The numbers of branches and distances between branches over time can be only quantified by these synchrotron images. Their interactions with mineral grains, existing pores and fractures, and the laminations, can be observed and characterized directly in the images (Figure 2). The spatial and temporal information are crucial in the development and application of mechanical theories and practical applications. For example, the supplementary information demonstrates that the assumptions commonly used to calculate $K_{\text {Ic }}$ from indentation experiments are invalidated by the form of the fractures developing in these experiments. This information would have been unavailable without the synchrotron imaging, leading to inaccurate $K_{\text {Ic }}$ measurements. Furthermore, synchrotron images allow DVC strain maps which provide information on strains developing during the deformation prior to fracture development (Figure 3). These tiny displacements are normally difficult to capture using standard methods, but play a key role in fracture prediction within these materials.

The representativity of micro-indentation in shale has often been questioned. Owing to the limited synchrotron beamtime, it is impossible to test hundreds of samples to present a substantial statistical analysis, but representativity has been demonstrated to be sufficient for fracture initiations and propagations in shales and can be supplemented by further laboratory measurements (further discussion is shown in section 4.3).

\subsection{The roles of bulk composition, laminations and orientation on fracture initiation and propagation}

Three variables were considered in this study as factors potentially controlling fracture initiation and propagation in shales during indentation: composition (carbonate, silicate, clay, and organic matter), laminations $(0,6,8,13$ laminae per $\mathrm{cm})$, and orientation relative to the bedding planes $\left(0^{\circ}, 45^{\circ}\right.$ and $\left.90^{\circ}\right)$.

\subsubsection{The role of bulk composition}

Shale composition shows the highest correlation with Vickers Hardness in this study, while it has low correlation with the density and separation of fractures when compared to laminations and orientation. This demonstrates that mean composition is one of the most important factors with respect to the hardness at the scale investigated, but it has less influence on the fracture propagation and final fracture patterns. It is noted that the compositions in this study are average compositions acquired from XRD and TOC rather than local compositions. Some studies show that higher clay mineral and kerogen contents lead to lower hardness (e.g. Abedi et al., 2016), but this is not a simple linear relationship. No relationship between hardness (Hv; GPa) and ductile material content (clay minerals and organic matter) is found at either $0^{\circ}$ (bedding perpendicular) or $90^{\circ}$ (bedding parallel), as demonstrated by the very low $R^{2}$ values shown in Figure 7 . There are presently few $45^{\circ}$ examples in the literature so this data is not plotted. Some studies suggest carbonate has greatest hardness, with an elastic modulus only half that of quartz and clay minerals (e.g. Kumar et al., 2012a). The BSF has the greatest percentage of carbonate (over 50\%) and a $H_{\mathrm{V}}$ value more than double any other sample for all orientations. Cement is commonly found in the matrix of BSF which is not seen in the other samples in this study. This may be the main reason for a greater $H_{\mathrm{V}}$. The KCF and WMF samples have similar concentrations of carbonate (less than $10 \%$ ) and also similar $H_{\mathrm{V}}$ ranges. The lowest $H_{\mathrm{V}}$ values appear in HBS due to the pre-existing cracks which significantly reduce the hardness. Combined with other studies, there is some suggestion that carbonate content leads to increasing $H_{\mathrm{V}}$ for bedding perpendicular samples, but there is no apparent relationship for bedding parallel samples (Figure $7 \mathrm{~B}$ and D). It is also noted 
the measurement deviation in contact area and the lag time of tomography taken after the initial fracture appearance may also lead to increasded uncertainty in Hv.
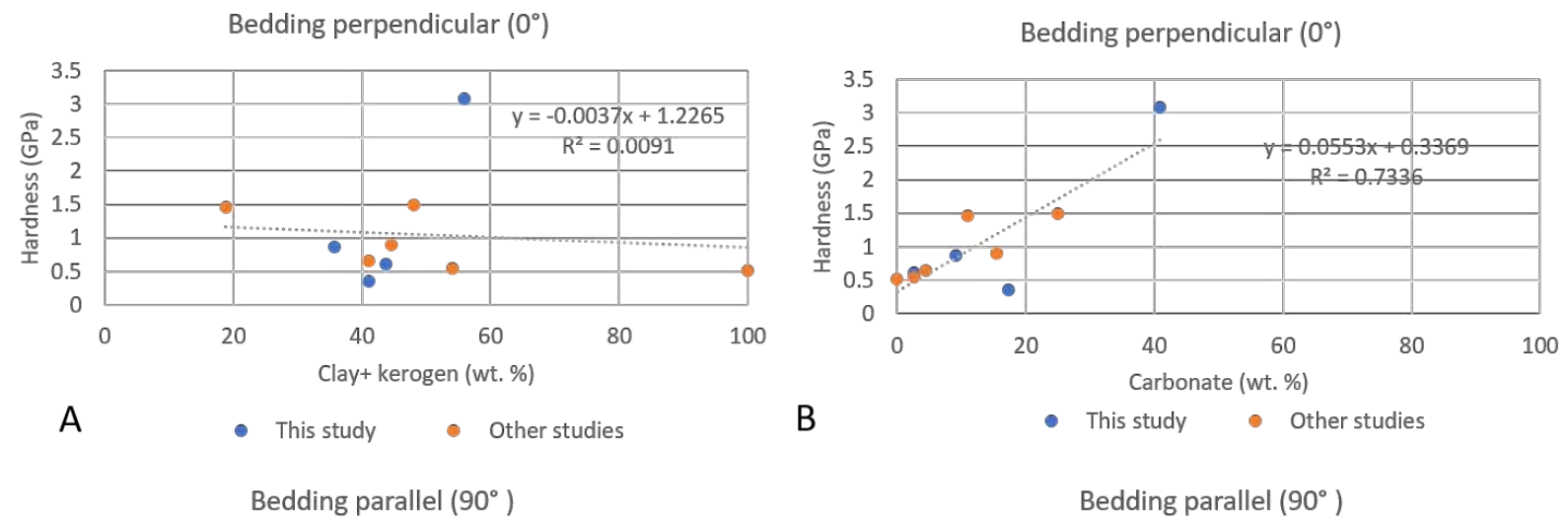

B

- This study Other studies
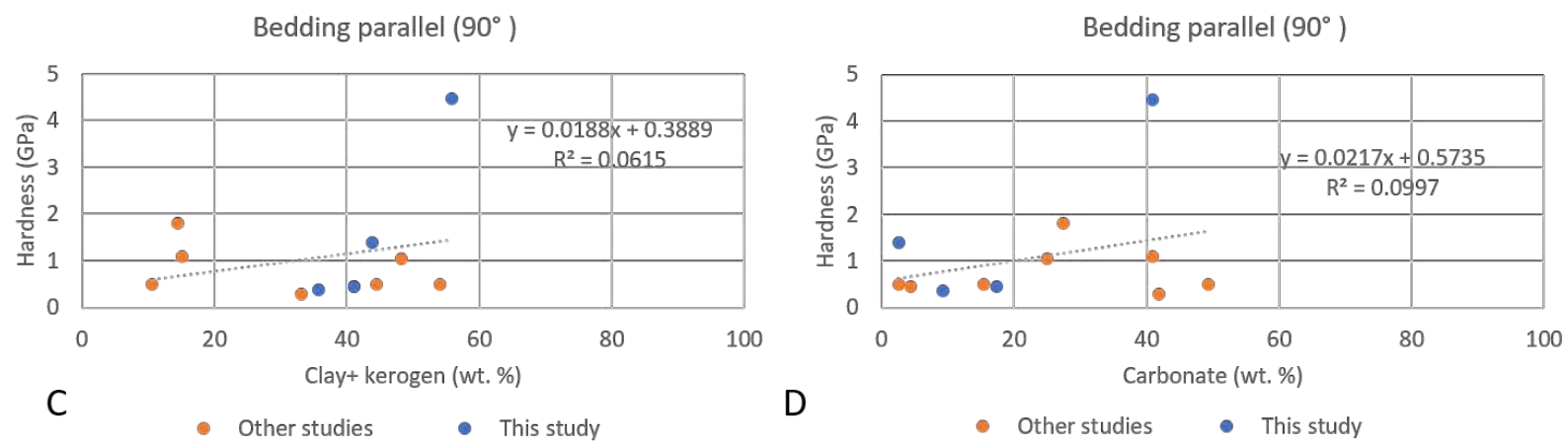

\section{Figure 7 Relations of Hardness (GPa) with ductile materials (clay and kerogen) and carbonate from this study and literatures (Abedi et al., 2016; Fan et al., 2019; Han et al., 2018) at two orientations.}

In summary, mineral compositions, when pre-existing cracks are not considered, affect the fracture initiation load and therefore play an important role in determining hardness of shales, but beyond this connection it is not a systematic control. Composition is therefore likely to act in combination with other rock properties such as porosity, grain sizes or arrangement within the matrix, to control the hardness (e.g. Herwanger* et al., 2015; Zhang et al., 2016).

\subsubsection{The role of texture}

The term texture refers to the geometric arrangement of grains in a sample (also termed as fabric). In this study, it is represented by lamination and its thickness. Texture has been seen to control the major direction of fracture propagation, and the numbers and scales of final fracture patterns (Figure 4). The correlations of lamination with nano-fractures are even higher than the micro-fractures but with lower significances. The LN13 HBS samples have higher ordered texture and therefore caused more branches and closer distance between them. In the highly cemented LN0 BSF samples, few nano-fractures were observed while in the laminated samples, both micro- and nano-fractures are present. The cement modified the original texture of the rocks, strengthening the matrix in LN0 sample and the cemented sample demonstrates relative isotropy but is not homogeneous (Figure $4 \mathrm{a}$ and $\mathrm{b}$ ). On the contrary, the laminae in the laminated samples cause anisotropy of many mechanical properties, including electrical 
resistivity, acoustic velocity, elastic moduli, Poisson's ratio and permeability (Rybacki et al., 2015; Waters et al., 2011). The geometry of micro-scale fractures therefore depends strongly on the thickness and arrangement of the laminae (Figure 5). This hypothesis is further demonstrated by the DVC stain maps displaying relatively uniform strain within a single lamina but strain discontinuities between laminae (Figure $4 \mathrm{c}$ and $\mathrm{d}$ ). Furthermore, the heterogeneous nature of shales means that the multi-scale texture important in the characterization of mechanical properties (e.g. Kumar et al., 2012b). Within a single lamina, the arrangement of 'hard' mineral grains and 'soft' mineral grains control the networks of nano-fractures (Figure 6). The fractures either bypass the round corners or branch at the sharp corner of the 'hard' minerals (e.g. carbonate grains), which promote the complex fracture patterns. When the secondary (either micro- or nano-) fractures, were created, they commonly propagate along the orientation of 'sheet' (e.g. clay) minerals. This suggests a relative consistency across scales in this study.

\subsubsection{The role of orientation}

The orientation of the loading direction relative to bedding controls the fracture propagation direction owing to anisotropy of the material properties (Chandler et al., 2016; Ibanez and Kronenberg, 1993). Also, the local arrangement of minerals under the indenters affect $H_{\mathrm{V}}$ of the samples, which affects fracture initialization. This can be observed in the DVC strain maps (Figure 3 and 4). Subsequently, the fractures tend to preferentially orient parallel to the bedding planes, when there is an angle between the loading and bedding directions (Figure 3 and 5). Apart from the BSF (LN0), the fractures in all other three samples at $45^{\circ}$ (bedding inclined) and $90^{\circ}$ (bedding parallel) propagated parallel to the bedding planes, while the fractures in samples oriented perpendicular to bedding deflected toward the bedding planes upon encountering an interface between two laminations (Figure 5). This kinking of fractures towards bedding interfaces has previously been observed in larger-scale mechanical experiments such as those of (Chandler et al., 2016), and (Forbes Inskip et al., 2018) and at microscale in the thermally induced fractures (Figueroa Pilz et al., 2017). The kinking depends on a combination of the incidence angle and toughness contrast at the interface. Therefore, in order to predict fracture propagation directions and geometries in future experiments or the subsurface, the anisotropy and texture, should be well characterized, over a range of scales. Figures 4 and 6 demonstrate that a fracture which appears straight at a given scale can be made up of a series of kinked segments at smaller scales.

\subsection{Multi-scale anisotropy and representative elementary volumes}

Shale heterogeneities are manifested from the nanoscale to the macroscopic scale, and observations and quantification across these scales is necessary to understand fracture initiation and propagation. Mineral composition (macroscopic feature) appears to be one of the factors controlling hardness (i.e. fracture initiation), while the texture (macroscopic feature) is considered to be the greatest factor influencing fracture propagation direction. Mechanical anisotropy is caused by both micro-scale texture (e.g. laminations and cement) and nano-scale texture (e.g. the size and arrangement of grains). Therefore the scale(s) of heterogeneity plays a major control over the development of multi-scale fracture patterns (Figure 4-6).

Representativity of the quantified feature is always considered in microstructural studies owing to the multi-scale nature of shales. Representative elementary volume (REV) is defined as a minimum averaging volume over which the macroscopic measurable characteristics are constant 
(Bear and Braester, 1972). REV was previously calculated in the same Bowland (Ma et al., 2016) and Haynesville (Ma et al., 2019) shale samples used in the present study as $380 \times 380 \times$ $380 \mu \mathrm{m}^{3}$ and $320 \times 320 \times 320 \mu \mathrm{m}^{3}$ respectively when pre-exiting microfractures are not present. The REVs of Kimmeridge and Whitby samples are assumed to be similar with Bowland and Haynesville samples based on the microscrope observations shown in Figure 6, which is also comparable with mechanical REV measured by other studies (e.g. Cosenza et al., 2019). Also, the discrepancy between the macromechanical modulus from micro-indentation was only less than $15 \%$ in Bakken Shale which has $(300 \mu \mathrm{m})^{2}$ representative elementary area (REA) (Liu et al., 2018), which demonstrates the representativity of micro-indentation is acceptable. The samples used in the in-situ experiments are around $3 \times 3 \times 3 \mathrm{~mm}^{3}$, which is over 10 times greater than the REVs and can cover two or more laminae. This suggests the fracture propagations quantified in these samples (in term of the sample sizes) are observed in representative volumes of microstructures. Additionally, the representativity can be further improved by combining with statistical analysis from grid indentation tests without imaging in future studies (Ortega et al., 2010).

\subsection{Implications for energy and environmental applications}

In-situ synchrotron imaging provides direct and multi-dimensional perspectives of the mechanical properties of materials. The combination of time-lapse tomography and DVC resolves the evolving deformation zone during indentation both qualitatively and quantitatively, and the strain maps are able to predict the fracture initiation and propagation directions and patterns.

Indentation perpendicular to bedding generates more fracture volume, while requiring a greater load. The fractures propagate further in relatively uniform-textured shales than in laminated shales. The results of this study suggest then, that under a given stress, the most extensive fracture network is likely to be induced in HBS, followed by WMF, KCF and finally BSF, although the effect of the in-situ stresses and fluid content is not considered. These synchrotron indentation results can therefore be applied in the design of fluid-injection treatments in hydrocarbon and other relevant reservoirs or in the safety assessment of the geological storage of carbon dioxide, hydrogen and nuclear waste.

\section{Conclusions}

We demonstrate the capability of capturing synchrotron images of fracturing initiation and propagation in shales during mechanical indentation using synchrotron X-ray tomography at the microscale. Hardness, fracture propagation and fracture geometries are examined for samples with varied compositions, microstructures, and orientations relative to the bedding planes. Compared with the standard indentation tests, synchrotron images provide additional dimensions to characterise and quantify the fracture propagation in the space and over time, and provide the possibility to quantify the deformation before cracking. This can provide a powerful quality control over mechanical measurements within inhomogeneous media, where underlying assumptions about the form of developing fractures are not necessarily valid. Furthermore, it is potentially impactful for developing fracturing theory and predictions of fracture development. 
This study suggests that in shales the average composition provides the major control on the hardness and fracture initiation, especially the carbonate content. Hardness increases from 0.35$3.08 \mathrm{GPa}$ in the bedding-perpendicular indentations with an increase of carbonate from 2.6- 52.4 $\%$ and a decrease in clay content from $36.6 \%$ to $3.5 \%$. The peak load ranges from $23.0-218.8 \mathrm{~N}$ to make the fracture initiation. The material texture and the orientation of the indentation to bedding combine to control the fracture propagation direction and geometry. It was found that microstructural features can govern the fractures at multiple scales. The cement in the matrix significantly increases the hardness and the fracture propagation directions. Fractures kink at the interface of two laminae at microscale, and the sub-branches deflected at round corns and split at the sharp ones at nanoscale. The initial deformation before fracturing were quantified by DVC, presenting evenly distribution in the unlaminated sample and heterogeneous distribution in laminated sample.

BSF samples have the highest hardness 3.08 to $4.46 \mathrm{GPa}$ and the fractures propagated directly to the sample base directly due to the microstructural homogeneity of the microfacies investigated. Fractures propagating perpendicular to bedding in KCF, WMF and HBS demonstrate fracture deflection toward the bedding planes at lamination interfaces and the fracture numbers largely depend on the laminae thickness. HBS samples have the lowest hardness $0.30-0.46 \mathrm{GPa}$ owing to the pre-existing fractures; newly formed fractures utilize the pre-existing fractures. For these materials at $45^{\circ}$ (bedding inclined) and $90^{\circ}$ (bedding parallel), the fractures propagated directly parallel to the bedding planes from initiation. Furthermore, in laminated samples nanoscale fractures can be observed after the experiment.

The technique established in this study provides guidance for in-situ imaging and quantification in more complex mechanical loading environments to simulate the realistic subsurface conditions. The results also demonstrate the micro- and nano- scale quantification must be considered in order to interpret the development of fracture networks in a wide range of applications, for example, in clean extractions of hydrocarbon energy, seasonal subsurface storage of hydrogen and heat, permanent geo-storage of carbon and nuclear waste and potentially predications of some fracture- related geo-hazards.

\section{Acknowledgements}

This project was funded in part by the UK-NERC (NE/M001458/1 and NE/R013527/1), the European Union's Horizon 2020 Program under the ShaleXenvironmenT project (grant no. 640979). Facilities at the Research Complex at Harwell are gratefully acknowledged, supported in part by the UK-EPSRC (EP/I02249X/1). Mr. Sebastian Marussi is acknowledged for technical support.

\section{References}

Aalto, P., Bilgin, M., Talus, K., 2017. The Political Economy Structures of Energy Transitions: from Shale Gas to Renewable Energy, Heading Towards Sustainable Energy Systems: Evolution or Revolution?, 15th IAEE European Conference, Sept 3-6, 2017. International Association for Energy Economics.

Abedi, S., Slim, M., Hofmann, R., Bryndzia, T., Ulm, F.-J., 2016. Nanochemomechanical signature of organic-rich shales: a coupled indentation-EDX analysis. Acta Geotechnica 11, 559-572. 
Arif, M., Lebedev, M., Barifcani, A., Iglauer, S., 2017. Influence of shale-total organic content on CO2 geo-storage potential. Geophysical Research Letters 44, 8769-8775. Bear, J., Braester, C., 1972. On the flow of two immscible fluids in fractured porous media, Developments in Soil Science. Elsevier, pp. 177-202.

Broitman, E., 2017. Indentation hardness measurements at macro-, micro-, and nanoscale: a critical overview. Tribology Letters 65, 23.

Buades, A., Coll, B., Morel, J.-M., 2005. A non-local algorithm for image denoising, Computer Vision and Pattern Recognition, 2005. CVPR 2005. IEEE Computer Society Conference on. IEEE, pp. 60-65.

Cai, B., Lee, P.D., Karagadde, S., Marrow, T.J., Connolley, T., 2016. Time-resolved synchrotron tomographic quantification of deformation during indentation of an equiaxed semi-solid granular alloy. Acta Materialia 105, 338-346.

Chandler, M.R., Fauchille, A.L., Kim, H.K., Ma, L., Mecklenburgh, J., Rizzo, R., Mostafavi, M., Marussi, S., Atwood, R., May, S., 2018. Correlative optical and X-ray imaging of strain evolution during Double Torsion Fracture Toughness measurements in shale. Journal of Geophysical Research: Solid Earth.

Chandler, M.R., Meredith, P.G., Brantut, N., Crawford, B.R., 2016. Fracture toughness anisotropy in shale. Journal of Geophysical Research: Solid Earth 121, 1706-1729. Charlet, L., Alt-Epping, P., Wersin, P., Gilbert, B., 2017. Diffusive transport and reaction in clay rocks: A storage (nuclear waste, $\mathrm{CO} 2, \mathrm{H} 2$ ), energy (shale gas) and water quality issue. Advances in Water Resources 106, 39-59.

Cosenza, P., Fauchille, A.-L., Prêt, D., Hedan, S., Giraud, A., 2019. Statistical representative elementary area of shale inferred by micromechanics. International Journal of Engineering Science 142, 53-73.

Fan, M., Jin, Y., Chen, M., Geng, Z., 2019. Mechanical characterization of shale through instrumented indentation test. Journal of Petroleum Science and Engineering 174, 607616.

Fauchille, A.-L., Hedan, S., Valle, V., Pret, D., Cabrera, J., Cosenza, P., 2016. Multiscale study on the deformation and fracture evolution of clay rock sample subjected to desiccation. Applied Clay Science 132, 251-260.

Fauchille, A., Hedan, S., Prêt, D., Valle, V., Cabrera, J., Cosenza, P., 2014. Relationships between desiccation cracking behavior and microstructure of the Tournemire clay rock by coupling DIC and SEM methods. Proceedings of IS on Geomechanics from Micro to Macro, Cambridge, IUK, 1421-1424.

Fauchille, A., Hédan, S., Valle, V., Prêt, D., Cabrera, J., Cosenza, P., 2019. Effect of microstructure on hydric strain in clay rock : a quantitative comparison. Applied Clay Science 182C.

Fauchille, A.L., Ma, L., Rutter, E., Chandler, M., Lee, P.D., Taylor, K.G., 2017. An enhanced understanding of the Basinal Bowland shale in Lancashire (UK), through microtextural and mineralogical observations. Marine and Petroleum Geology. Feng, Y., Jones, J.F., Gray, K.E., 2016. A Review on Fracture-Initiation and Propagation Pressures for Lost Circulation and Wellbore Strengthening. SPE Drilling \& Completion 31, 134-144.

Figueroa Pilz, F., Dowey, P.J., Fauchille, A.L., Courtois, L., Bay, B., Ma, L., Taylor, K.G., Mecklenburgh, J., Lee, P.D., 2017. Synchrotron tomographic quantification of strain and fracture during simulated thermal maturation of an organic-rich shale, UK 
Kimmeridge Clay. Journal of Geophysical Research: Solid Earth 122, 2553-2564. Forbes Inskip, N.D., Meredith, P.G., Chandler, M.R., Gudmundsson, A., 2018. Fracture Properties of Nash Point Shale as a Function of Orientation to Bedding. Journal of Geophysical Research: Solid Earth 123, 8428-8444.

Guo, Z., Chapman, M., Li, X., 2012. Exploring the effect of fractures and microstructure on brittleness index in the Barnett Shale, SEG Technical Program Expanded Abstracts 2012. Society of Exploration Geophysicists, pp. 1-5.

Han, Q., Qu, Z., Ye, Z., 2018. Research on the mechanical behaviour of shale based on multiscale analysis. Royal Society open science 5, 181039.

Hawthorn, D., Maquaker, J., Rutter, E.H., Sciences, U.o.M.D.o.E., 2004. An Experimental Study of the Permeability of Kimmeridge Clay Mudstone. University of Manchester.

Hedan, S., Valle, V., Cabrera, J., Cosenza, P., 2018. A new approach to quantify the anisotropy of hydromechanical strains in clay-rock at the gallery scale. International Journal of Rock Mechanics and Mining Sciences 111, 45-53.

Herwanger*, J.V., Bottrill, A.D., Mildren, S.D., 2015. Uses and abuses of the brittleness index with applications to hydraulic stimulation, Unconventional Resources Technology Conference, San Antonio, Texas, 20-22 July 2015. Society of Exploration Geophysicists, American Association of Petroleum Geologists, Society of Petroleum Engineers, pp. 1215-1223.

Ibanez, W.D., Kronenberg, A.K., 1993. Experimental deformation of shale: Mechanical properties and microstructural indicators of mechanisms, International journal of rock mechanics and mining sciences \& geomechanics abstracts. Elsevier, pp. 723-734. Karagadde, S., Lee, P., Cai, B., Fife, J.L., Azeem, M., Kareh, K., Puncreobutr, C., Tsivoulas, D., Connolley, T., Atwood, R.C., 2015. Transgranular liquation cracking of grains in the semi-solid state. Nature communications 6, 8300.

Kareh, K., Lee, P., Atwood, R., Connolley, T., Gourlay, C., 2014. Revealing the micromechanisms behind semi-solid metal deformation with time-resolved X-ray tomography. Nature communications 5, 4464.

Kline, S., McClintock, F., 1953. Describing Uncertainties in Single-Sample Experiments. Mechanical Engineering 75, 3-8.

Kumar, V., Curtis, M.E., Gupta, N., Sondergeld, C.H., Rai, C.S., 2012a. Estimation of elastic properties of organic matter in Woodford Shale through nanoindentation measurements, SPE Canadian Unconventional Resources Conference. Society of Petroleum Engineers.

Kumar, V., Sondergeld, C.H., Rai, C.S., 2012b. Nano to Macro Mechanical Characterization of Shale, SPE Annual Technical Conference and Exhibition. Society of Petroleum Engineers, San Antonio, Texas, USA, p. 23.

Lee, H.P., Olson, J.E., Holder, J., Gale, J.F., Myers, R.D., 2015. The interaction of propagating opening mode fractures with preexisting discontinuities in shale. Journal of Geophysical Research: Solid Earth 120, 169-181.

Liu, K., Ostadhassan, M., Bubach, B., Ling, K., Tokhmechi, B., Robert, D., 2018.

Statistical grid nanoindentation analysis to estimate macro-mechanical properties of the Bakken Shale. Journal of Natural Gas Science and Engineering 53, 181-190.

Lovell, A.E., Srinivasan, S., Karra, S., O'Malley, D., Makedonska, N., Viswanathan, H.S., Srinivasan, G., Carey, J.W., Frash, L., 2018. Extracting hydrocarbon from shale: 
An investigation of the factors that influence the decline and the tail of the production curve. Water Resources Research 54, 3748-3757.

Ma, L., Dowey, P.J., Rutter, E., Taylor, K.G., Lee, P.D., 2019. A novel upscaling procedure for characterising heterogeneous shale porosity from nanometer-to millimetre-scale in 3D. Energy.

Ma, L., Fauchille, A.-L., Dowey, P.J., Pilz, F.F., Courtois, L., Taylor, K.G., Lee, P.D., 2017. Correlative multi-scale imaging of shales: a review and future perspectives. Geological Society, London, Special Publications.

Ma, L., Slater, T., Dowey, P.J., Yue, S., Rutter, E.H., Taylor, K.G., Lee, P.D., 2018. Hierarchical integration of porosity in shales. Scientific Reports 8, 11683.

Ma, L., Taylor, K.G., Lee, P.D., Dobson, K.J., Dowey, P.J., Courtois, L., 2016. Novel 3D centimetre-to nano-scale quantification of an organic-rich mudstone: The Carboniferous Bowland Shale, Northern England. Marine and Petroleum Geology 72, 193-205.

McKernan, R., Mecklenburgh, J., Rutter, E., Taylor, K., 2017. Microstructural controls on the pressure-dependent permeability of Whitby mudstone. Geological Society, London, Special Publications 454, SP454. 415.

Mo, J., Guo, E., McCartney, D., Eastwood, D., Bent, J., Van Dalen, G., Schuetz, P., Rockett, P., Lee, P., 2018. Time-Resolved Tomographic Quantification of the Microstructural Evolution of Ice Cream. Materials 11, 2031.

Nezhad, M.M., Fisher, Q.J., Gironacci, E., Rezania, M., 2018. Experimental study and numerical modeling of fracture propagation in shale rocks during Brazilian disk test. Rock Mechanics and Rock Engineering 51, 1755-1775.

Ortega, Ulm, Abousleiman, 2010. A Multi-scale Micromechanics Framework For Shale Using Nano-tools. American Rock Mechanics Association.

Ren, J., Tan, S., Goodsite, M.E., Sovacool, B.K., Dong, L., 2015. Sustainability, shale gas, and energy transition in China: assessing barriers and prioritizing strategic measures. Energy 84, 551-562.

Rutter, E.H., Mecklenburgh, J., 2017. Hydraulic conductivity of bedding-parallel cracks in shale as a function of shear and normal stress. Geological Society, London, Special Publications 454, SP454. 459.

Rybacki, E., Reinicke, A., Meier, T., Makasi, M., Dresen, G., 2015. What controls the mechanical properties of shale rocks? - Part I: Strength and Young's modulus. Journal of Petroleum Science and Engineering 135, 702-722.

Titarenko, S., Withers, P.J., Yagola, A., 2010. An analytical formula for ring artefact suppression in X-ray tomography. Applied Mathematics Letters 23, 1489-1495.

Waters, G.A., Lewis, R.E., Bentley, D., 2011. The Effect of Mechanical Properties Anisotropy in the Generation of Hydraulic Fractures in Organic Shales, SPE Annual Technical Conference and Exhibition. Society of Petroleum Engineers, Denver, Colorado, USA, p. 25.

Zhang, D., Ranjith, P., Perera, M., 2016. The brittleness indices used in rock mechanics and their application in shale hydraulic fracturing: A review. Journal of Petroleum Science and Engineering 143, 158-170. 